\title{
P-nitrofenol'ün elektrokimyasal yöntemle belirlenmesi için esnek ve müstakil PtCu ile modifiye edilmiş grafen esaslı kağıt
}

\author{
A flexible and self-standing PtCu modified graphene-based paperfor detection of p- \\ nitrophenol with electrochemical method
}

\author{
Kader DAĞCI KIRANŞAN*1,a, Ezgi TOPÇU ${ }^{1, b}$, \\ ${ }^{1}$ Atatürk Üniversitesi, Fen Fakültesi, Kimya Bölümü, 25240 Erzurum
}

• Geliş tarihi / Received: 24.05.2020 • Düzeltilerek geliş tarihi / Received in revised form: $11.11 .2020 \quad$ • Kabul tarihi / Accepted: 10.12 .2020

\begin{abstract}
Öz
$\mathrm{Bu}$ çalışmada; esnek, müstakil ve dayanıklı $\mathrm{PtCu}$ /indirgenmiş grafen oksit (iGrO) hibrit kağıt sentezlenmiş ve pnitrofenolün (PNP) elektrokimyasal olarak tespiti için kullanılmıştır. $\mathrm{PtCu} / \mathrm{iGrO}$ hibrit kağıt, $\mathrm{PtCu}$ alaşım nanokompozit yapısının iGrO kağıt elektrot üzerine elektrokimyasal olarak kaplanmasıyla üretilmiştir. Elde edilen $\mathrm{PtCu} / \mathrm{iGrO}$ hibrit kağıt, taramalı elektron mikroskobu, X-1̧̧ını kırınım spektroskopisi, X-1şını fotoelektron spektroskopisi, Raman spektroskopisi, elektrokimyasal empedans spektroskopisi ile karakterize edildi. $\mathrm{PtCu} / \mathrm{iGrO}$ hibrit kağıdının morfolojik analizi, iGrO elektrot yüzeyinde oluşan çiçek benzeri nanoyapıların çok sayıda keskin kenarlı $\mathrm{PtCu}$ nanotabakalarından oluştuğunu göstermiştir. PNP'nin elektrokimyasal belirlenmesinde kullanılan, $\mathrm{PtCu} / \mathrm{iGrO}$ hibrit kağıt elektrotun, iGrO kağıda kıyasla yüksek elektrokatalitik performans, geniş doğrusal aralık $(0.08-760 \mu \mathrm{M})$ ve düşük algılama limiti $(0.022$ $\mu \mathrm{M})$ sergilediği belirlenmiştir. PtCu/iGrO hibrit kağıt sensör ayrıca musluk suyunda PNP tespiti için yüksek geri kazanım değerleri göstermiştir. Pratik ve uygulanması kolay bir yöntem ile hazırlanan hibrit kağıt sensörü mekanik olarak esnek ve dayanık özellik sergilemiştir. Ayrıca, PtCu/iGrO kağıdın stabilite testleri, bu hibrit elektrotun yüksek performanslı esnek sensör uygulamaları için önemli bir aday olduğunu göstermiştir.
\end{abstract}

Anahtar kelimeler: Elektrokimyasal sensör, Esnek materyal, Grafen esaslı kağıt, P-nitrofenol, PtCu alaşım nanokompozit

\begin{abstract}
In this study; a flexible, self-contained and durable PtCu/reduced graphene oxide (iGrO) hybrid paper was synthesized and used for the electrochemical detection of p-nitrophenol (PNP). PtCu/iGrO hybrid paper was fabricated through electrodeposition of PtCu composite structure on iGrO paper electrode. The obtained PtCu/iGrO hybrid paper was characterized by field emission scanning electron microscopy (FESEM), X-ray diffraction spectroscopy (XRD), X-ray photoelectron spectroscopy (XPS), Raman spectroscopy, electrochemical impedance spectroscopy. The morphological analysis of PtCu/iGrO hybrid paper showed that flower-like nanostructures formed on the iGrO electrode surface consist of numerous sharp-edged nano layer of PtCu. PtCu/iGrO hybrid paper electrode demonstrated high electrocatalytic performance compared to iGrO paper and exhibited a wide linear range $(0.08-760 \mu M)$ and a low detection limit $(0.022$ $\mu M)$ for the determination of PNP. The PtCu/iGrO hybrid paper sensor also showed high recovery values for PNP detection in tap water. The hybrid paper sensor prepared with a practical and easy-to-apply method exhibited mechanically flexible and durable properties. Moreover, stability tests of $\mathrm{PtCu} / \mathrm{iGrO}$ paper displayed that this hybrid electrode is an important candidate for high-performance flexible sensor applications.
\end{abstract}

Keywords: Electrochemical sensor, Flexible material, Graphene-based paper, P-nitrophenol, PtCu alloy nanocomposite

\footnotetext{
*a Kader DAĞCI KIRANŞAN; kdagci@atauni.edu.tr, Tel: (0442)231 44 36, https://orcid.org/0000-0002-0764-9393

${ }^{\mathrm{b}}$ orcid.org/0000-0003-1506-9089
} 


\section{Giriş}

Nitrofenoller, boya, ilaç ve pestisit üretiminde yaygın olarak kullanılan bir toksik, antropojenik, refrakter ve inhibitör organik bileşik sınıfıdır (Umamaheswari ve Venkateswarlu, 2004; Schummer vd., 2009). P-nitrofenol (PNP), bu ailenin ABD Çevre Koruma Ajansı tarafindan öncelikli toksik kirleticiler listesinde belirtilen üyelerinden biridir (Yu vd., 2010). PNP, tatl su ve deniz ortamlarının yanı sıra endüstriyel atık sularda da bulunabilen bir bileşiktir. Bu nedenle, sulu çözeltilerde PNP'nin eser analizi için basit ve güvenilir bir yöntem geliştirmek büyük önem taşımaktadır (Zhang vd., 2007; Liu vd., 2008). PNP'nin tespitinde, gaz ve sivi kromatografisi (Puig vd., 1997), UV-vis spektrofotometrisi (Norwitz vd., 1986) ve floresans (Nistor vd., 2001) gibi yöntemler kullanılmaktadır. Ancak bu yöntemler karmaşı enstrümental analizler ve test süreçleri veya uzun süreli analizler gerektirdiğinden pratik kullanım için uygun değildir. Elektrokimyasal yöntemler, uygulama kolaylığı, hızlı cevap süresi ve yerinde tespit olanağı gibi büyük avantajları nedeniyle PNP'nin belirlenmesinde büyük ilgi görmektedir.

PNP'nin elektrokimyasal yöntemle belirlenmesi ile ilgili pek çok çalışma olmasına karşılık, genel olarak katı bir destek materyali üzerine farklı özelliklere sahip yapılar immobilize edilerek hazırlanan modifiye elektrotlar kullanılmaktadır. Günümüzde minyatürize edilebilen ve teknolojik uygulamalara kolay adapte olabilecek elektrotların hazırlanması oldukça büyük önem arz etmektedir. $\mathrm{Bu}$ sebepten dolayı son yıllarda başta teknolojik uygulamalar olmak üzere pek çok alanda esnek yapıya sahip, eğilebilir, bükülebilir, kesilebilir ve katlanabilir materyallerin hazırlanması ve kullanımı üzerine yapılan araştırmalar ivme kazanmıştır (Dağcı Kıranşan ve Topçu, 2020). Bu şekilde hazırlanabilen materyallerin başında grafen gelmektedir.

Son y1llarda, grafen esaslı kağıt elektrotlar elektrokimyasal çalışmalarda büyük ilgi görmüştür. Bunun nedeni; bu esnek malzemelerin daha fazla akım yoğunluğu sağlaması ve büyük elektroaktif yüzeyi nedeniyle geleneksel elektrotlara göre daha avantajlı olmasıdır (Topçu vd., 2016; Dağc1 Kuranşan vd., 2017; Dağc1 Kıranşan ve Topçu, 2018). Ayrıca, grafen esaslı kağıtların kesilebilir ve şekillendirilebilir özellikleri birçok uygulamada kullanımlarını kolaylaştırmaktadır (Ge vd., 2015; Dağc1 Kıranşan vd., 2018; Dağc1 Kıranşan ve Topçu, 2019). Bunların yanı sıra, grafen esaslı kağıtlar; polimerler, metal oksitler, metal sülfitler, karbon bazlı veya nanoyapılı malzemelerle entegre olduklarında kolektif ve sinerjik özellik gösterirler (Topçu ve Dağcı Kıranşan, 2019, 2020). Bu bağlamda, grafenin farklı inorganik ve organik yapılar ile kombinasyonu yüksek elektronik, optik ve mekanik özellikler sergilemesinden dolayı büyük ilgi görmektedir (Topçu, 2020). Grafen esaslı kağıtlar mükemmel stabiliteye sahiptir ve kataliz (Yan vd., 2019; Topçu ve Dağc1 Kıranșan, 2018), enerji depolama (Chi vd., 2014), süperkapasitör (Wang vd., 2009) ve sensör (Dağc1 ve Alanyalıoğlu, 2016; Dağcı Kıranşan, 2019) gibi uygulamalarında karşımıza çıkmaktadır.

Grafen esaslı kağıt materyallerin katalitik performanslarının artırılması için, yüzeyleri farklı kompozisyona sahip yapılar ile kaplanarak kompozit ve hibrit materyaller elde edilmektedir. $\mathrm{Bu}$ amaçla grafen esası kağıtlar farklı materyaller ile modifiye edilerek kompozit yapilar hazırlanmıştır. Grafen kağıtların modifikasyonlarında kullanılan materyallerden birisi de alaşım oluşturan metal nanokompozitlerdir (Zhong vd., 2019; Loudhaief vd., 2020). Alaşım nanokompozitler çoğunlukla kataliz çalışmalarında kullanılmak üzere tasarlanmaktadır. Elektrokataliz çalışmalarında en fazla tercih edilen metal Pt'dir. Pt'nin farklı metaller ile alaşımı yapılarak hem maliyetin azalması hem de hazırlanan nanokompozit yapının elektrokimyasal peformasının yüksek olması sağlanmaktadır. $\mathrm{PtCu}$ alaşım nanokompozit yapısı, özellikle anodik bölgede yüksek elektrokimyasal performansa sahip olduğu için, son yıllarda bu alandaki uygulamalarda sıklıkla karşımıza çıkmaktadır (Zhao vd., 2016).

Bu çalışmada esnek, iki boyutlu (2D) ve müstakil $\mathrm{PtCu} / \mathrm{iGrO}$ hibrit kağıt, iGrO kağıt yüzeyinin $\mathrm{PtCu}$ alaşım nanoyapısı ile elektrokimyasal olarak kaplanmasıyla sentezlenmiştir. Hazırlanan $\mathrm{PtCu} / \mathrm{iGrO}$ hibrit kağıt materyalin yapısal ve morfolojik özellikleri karakterize edilerek, önerilen kompozisyonda başarılı bir şekilde sentezlendiği belirlenmiştir. Esnek $\mathrm{PtCu} / \mathrm{iGrO}$ hibrit kağıt elektrot, PNP'nin amperometrik tayininde kullanılmış ve bu müstakil elektrokimyasal sensör, destekli sensör materyaller ile kıyaslandığında yüksek hassasiyet, düşük tespit limiti ve geniş doğrusal aralık sergilemiştir. Ayrıca, $\mathrm{PtCu} / \mathrm{iGrO}$ kağıt sensörün dayanıklılık ve esneklik açısından yüksek performansa sahip olması, modüler yaklaşımlarda uygulanabilir olduğunu göstermiştir. 


\section{Materyal ve metot}

\subsection{Kullanılan kimyasallar}

Tüm kimyasallar Sigma-Aldrich'ten satın alınmıştır ve analitik reaktif derecede saftır. Bütün deneylerde distile su kullanılmıştır. Farklı $\mathrm{pH}$ değerlerinde hazırlanan ve kullanılan fosfat tampon çözeltilerini hazırlamak için $\mathrm{Na}_{2} \mathrm{HPO}_{4}$ ve $\mathrm{NaH}_{2} \mathrm{PO}_{4}$ tuzları kullanılmıștır. Tüm standart PNP çözeltileri fosfat tampon çözeltisi içinde hazırlanmıştır ( $\mathrm{pH} 7.5)$.

\section{2. iGrO kağıdın hazırlanması}

GO sentezlemek için modifiye Hummers yöntemi kullanılmıştır (Sreeprasad vd., 2009). $100 \mathrm{~mL}$ iGrO (1.0 $\mathrm{mg} \mathrm{mL}^{-1}$ ) süspansiyonu, ultrafiltrasyon vakum hücresi kullanılarak bir polikarbonat membran filtreden süzülmüştür. iGrO kağıt, yıkama ve kurutmadan sonra membrandan ayrilarak elde edilmiştir. iGrO kağıt 1 saat boyunca \%57'lik (a/a) hidrojen iyodür (HI) çözeltisine daldırılarak kimyasal bir indirgeme sağlanmış ve böylece iGrO kağıt elde edilmiştir. iGrO kağıt damıtılmış su ve etanol ile yıkandıktan sonra havada kurutulmuştur. Her seferinde yaklaşık $47 \mathrm{~mm}$ 'lik bir yarıçapla hazırlanan bu iletken iGrO kağıt, şerit şeklinde (20 $\mathrm{mm} \quad \mathrm{x} \quad 5 \quad \mathrm{~mm}$ ) kesilerek elektrokimyasal çalışmalarda doğrudan elektrot olarak kullanılmıştır.

\subsection{PtCu kristallerinin sentezi}

$\mathrm{PtCu}$ alaşım nanokompozitini hazırlamak için, 0.1 $\mathrm{mM}$ amonyum tuzu $0.1 \mathrm{M} \mathrm{HCl}$ içerisinde çözülerek hazırlanan çözelti içerisine $1.3 \mathrm{mg}$ susuz $\mathrm{CuSO}_{4}$ ve $0.05 \mathrm{mg} \mathrm{H}_{2} \mathrm{PtCl}_{6}$ ilave edilerek, yaklaşık yarım saat ultrasonikasyon işlemi uygulanmıştır. Elde edilen çözelti teflon otoklav içerisine alınarak $180^{\circ} \mathrm{C}^{\prime} \mathrm{de} 6$ saat hidrotermal işlem gerçekleştirilmiştir. Hidrotermal işlemin ardından elde edilen ürün süzülmüş, yıkanmış ve $60^{\circ} \mathrm{C}^{\prime} \mathrm{de}$ kurutulmuştur (Zhong vd., 2019).

\subsection{PtCu/iGrO hibrit kağıdın elektrokimyasal sentezi}

$20 \mathrm{~mL}$ dimetilformamid (DMF: $\mathrm{C}_{3} \mathrm{H}_{7} \mathrm{NO}$ ) içerisinde $0.05 \mathrm{M} \mathrm{NaOH}$ olacak şekilde hazırlanan çözeltiye $10 \mathrm{mg} \mathrm{PtCu}$ alaşım nanokompozit yapısı ilave edilmiş ve hazırlanan karışım yaklaşık 1 saat ultrasonik işleme tabi tutulmuştur. Hazırlanan dispersiyon elektrokimyasal hücreye alınmış ve iGrO kağıt yüzeyine $\mathrm{PtCu}$ alaşım nanoyapısının kaplanması için 0 ila $-1300 \mathrm{mV}$ potansiyelleri arasında dönüşümlü voltametri (CV) tekniği uygulanmıştır (Dağc1 Kıranşan ve Topçu, 2019). Elde edilen kağıt materyal $\mathrm{PtCu} / \mathrm{iGrO}$ hibrit kağıt olarak adlandırılmıştır.

\subsection{Kullanılan cihazlar ve elektrokimyasal yöntemler}

$\mathrm{PtCu} / \mathrm{iGrO}$ hibrit kağıdın morfolojik yapısı ZEISS SIGMA 300 marka FESEM-EDS cihazı ile incelenmiștir. XRD spektrumları, monokromatize $\mathrm{Cu} \mathrm{K} \alpha$ radyasyonuna $(\lambda=1.5406 \AA)$ sahip bir Rigaku TTR III X 1şını difraktometresi ile elde edilmiştir. XPS ölçümleri, standart Al X 1şın kaynağına sahip bir Spect-Flex spektrometresi ile ve Raman spektrumları, oda sicaklığında WITech alpha 300R marka mikro-Raman spektrometresi ile elde edilmiştir.

$\mathrm{CV}$, elektrokimyasal empedans spektroskopisi (EIS) ve kronoamperometri deneyleri için üç elektrotlu bir hücreye bağlı Epsilon (BASi) ve Gamry $(600+)$ potansiyostat sistemleri kullanılmıştır. Çalışma elektrodu için: $20 \mathrm{~mm}$ x 5 $\mathrm{mm}$ (uzunluk $\mathrm{x}$ genişlik) boyutlarında kesilmiş iGrO kağıt, bir Pt levha arasına yerleştirilmiş ve bir timsah klipsi ile tutturulmuştur. Kağıt elektrotun yaklaşık üçte biri, Pt ve klipsin çözelti ile temasını önlemek için Teflon bant (iletken olmayan) ile sarılmıştır (Şekil 1a). Bahsedilen elektrokimyasal hücrede, bir Pt tel, karşıt elektrot ve $\mathrm{Ag} / \mathrm{AgCl}$ referans elektrot olarak kullanılmıştır (Şekil 1b). $\mathrm{CV}$ ve EIS testleri Gamry $(600+)$ potansiyostat sistemi ile yapılmış ve EIS, $5 \mathrm{mV}$ AC voltaj açık devre potansiyelinde 0.1 ila $1 \times 10^{5} \mathrm{~Hz}$ frekans aralığında çalışılmıştır. iGrO kağıt elektrot, direk elektrokimyasal hücrede çalışma elektrodu olarak kullanılarak yüzeyinin elektrokimyasal olarak $\mathrm{PtCu}$ nanokompozit yapis1 ile kaplanması sağlanmıştır. PNP'nin elektrokimyasal tayinide kullanılan $\mathrm{PtCu} / \mathrm{iGrO}$ hibrit elektrotun etkin yüzey alanı, dönüşümlü voltametri (CV) tekniği kullanilarak, $10 \mathrm{mM} \mathrm{K}_{3} \mathrm{Fe}(\mathrm{CN})_{6}$ ve $0.1 \mathrm{M} \mathrm{KCl}$ içeren bir çözeltide $\mathrm{Fe}(\mathrm{CN})_{6}^{3-} / \mathrm{Fe}(\mathrm{CN})_{6}{ }^{4-}$ redox sisteminin elektrokimyasal davranışı dikkate alınarak hesaplanmıştır. Etkin elektrot yüzey alanın hesaplamaları için Randles-Sevcik denklemi kullanılmıştır.

$i p=268.600 n^{3 / 2} A D^{1 / 2} C v^{1 / 2}$

Randles-Sevcik denklemi ip pik akımı (A); $n$ redoks reaksiyonunda transfer edilen elektron sayıs1; $A$ elektrot yüzey alanı $\left(\mathrm{cm}^{2}\right) ; F$ Faraday sabiti $\left(96485{\mathrm{C} . \mathrm{mol}^{-1}}^{-1}\right) ; D$ ferrisiyanür iyonları için difüzyon katsayıs1 $\left(7.60 \times 10^{-6} \quad \mathrm{~cm}^{2} / \mathrm{s}\right) ; \quad C$ Konsantrasyon $\left(\mathrm{mol} / \mathrm{cm}^{3}\right) ;$ v tarama hızı $(\mathrm{V} / \mathrm{s})$ ' dır. 
$\mathrm{Bu}$ denklem incelendiğinde, $\mathrm{n}, \mathrm{D}, \mathrm{F}, \mathrm{C}$ ve v aynı elektrokimyasal sistemde sabit olan değişkenler oldukları için akım oluşumuna etki eden temel parametrenin A yani etkin elektrot yüzey alanı olduğu görülmektedir. Böylece hazırlanan $\mathrm{PtCu} / \mathrm{iGrO}$ hibrit elektrotlar PNP'nin elektrokimyasal tayininde kullanıldıktan sonra, etkin yüzey alanları yukarıda anlatıldığ 1 şekilde belirlenmiş, akım değerleri elde edilen yüzey alanına bölünerek akım yoğunluğu (Akım/etkin yüzey alanı) olarak sunulmuştur. Böylece her elektrokimyasal analiz sonucu akım yoğunluğu olarak sunularak, tekrarlanabilir sonuçlar elde edilmiş ve oluşabilecek hatalar azaltılmıştır. (a)

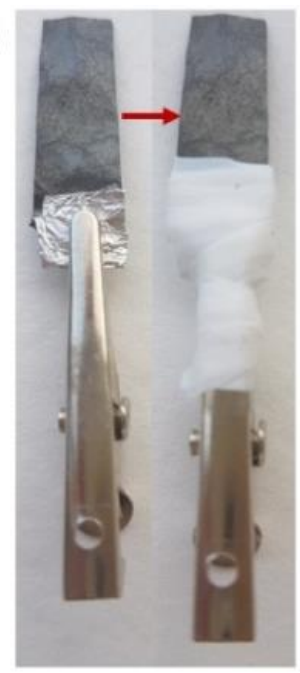

iGrO kağıt elektrot

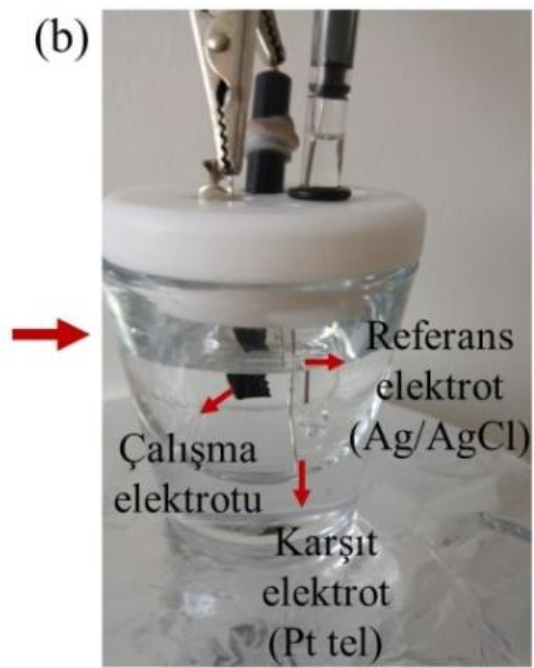

Elektrokimyasal sistem

Şekil 1. (a) Çalışma elektrodu olarak hazırlanan iGrO kağıt elektrodun, (b) elektrokimyasal sistemin fotoğrafları

\section{Bulgular ve tartışma}

\section{1. PtCu/iGrO hibrit kă̆ıdın karakterizasyonu}

$\mathrm{PtCu} / \mathrm{iGrO}$ kağıdın hazırlanmasına ait temsili gösterim Şekil 2'de sunulmuştur. Şekil 2'de iGrO kağıdın oldukça esnek ve dayanıklı bir yapıda olduğu gözlenmiştir. Dikdörtgen şeklinde kesilerek hazırlanan iGrO kağıdın yüzeyi elektrokimyasal sistemde $\mathrm{PtCu}$ alaşım nanoyapısı ile kaplanmıştır.

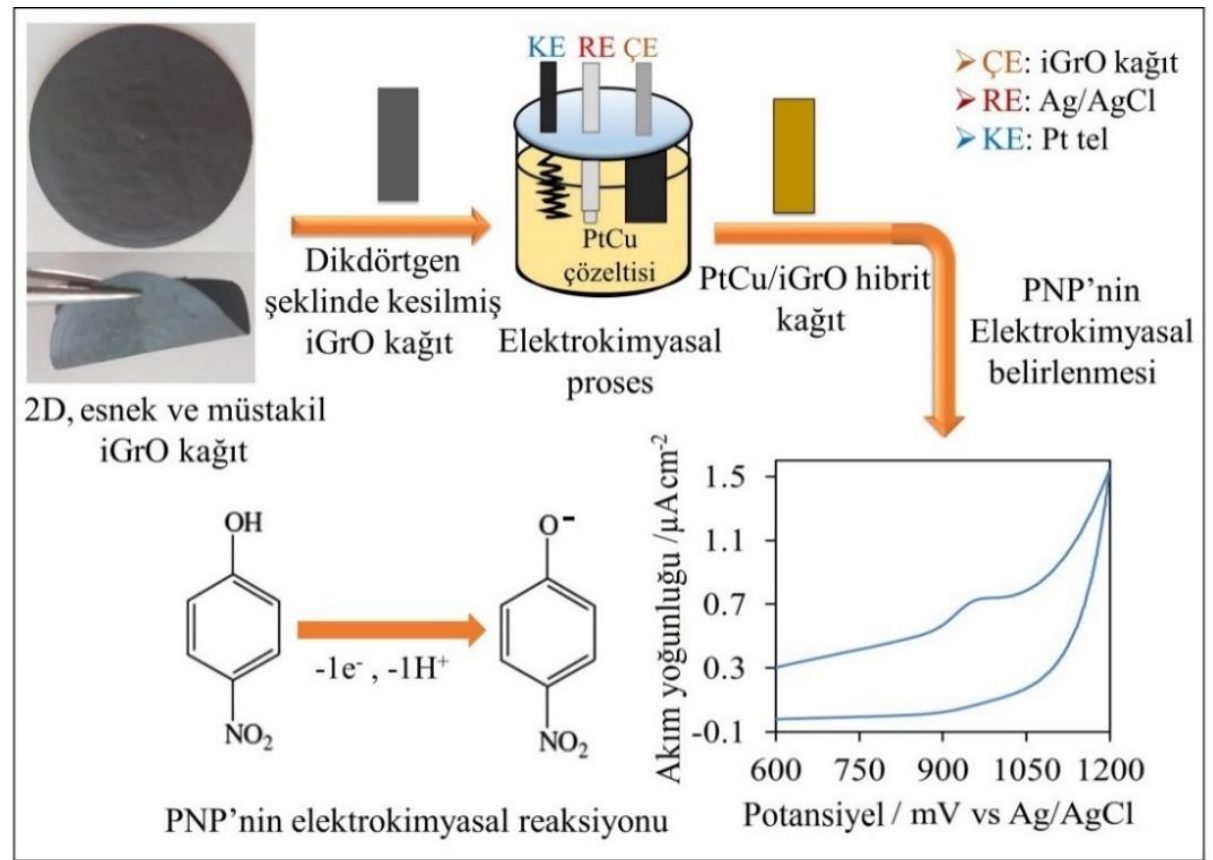

Şekil 2. $\mathrm{PtCu} / \mathrm{iGrO}$ hibrit kağıdın hazırlanmasına ait temsili gösterimi ve PNP'nin elektrokimyasal oksidasyonu (ÇE: Çalışma elektrodu, RE: Referans elektrot, KE: Karşıt elektrot) 
Karakteristik buruşuk iGrO kağıt yüzeyinin (Şekil 3a) $\mathrm{PtCu}$ yapıları ile kaplanmasiyla hazırlanan $\mathrm{PtCu} / \mathrm{iGrO}$ hibrit kağıdın FESEM görüntüsü Şekil $3 \mathrm{~b}$ ve c'de sunulmuştur. iGrO kağıda ait yüzey FESEM görüntüsü incelendiğinde, yüzeyini karakteristik kırışık çarşaf benzeri grafen yapısından oluştuğu görülmektedir (Dağc1 ve Alanyalığlu, 2016) PtCu/iGrO hibrit kağıda ait FESEM görüntüleri incelendiğinde, yüzeyde keskin kenarlı, düzlem tabaka şeklinde $\mathrm{Pt}$ nanopartikülleri ile beraber nanotop benzeri $\mathrm{Cu}$ yapılarının oluştuğu gözlenmiştir. Böylece yüzeyde homojen bir şekilde ve oldukça pürüzlü bir yapıda $\mathrm{PtCu}$ alaşım nanoyapısının oluştuğu belirlenmiştir. $\mathrm{PtCu} / \mathrm{iGrO}$ hibrit kağıdın yüzeyinde bulunan, pürüzlü ve keskin kenarlı düzlemsel yapılardan dolayı oldukça yüksek aktif yüzey alanı sağlayacağı öngörülmüştür. Şekil 3d'de sunulan EDX spektrumunda ise $\mathrm{PtCu} / \mathrm{iGrO}$ hibrit kağıdın $\mathrm{C}, \mathrm{O}, \mathrm{Pt}$ ve $\mathrm{Cu}$ atomlarını içerdiği belirlenmiştir.

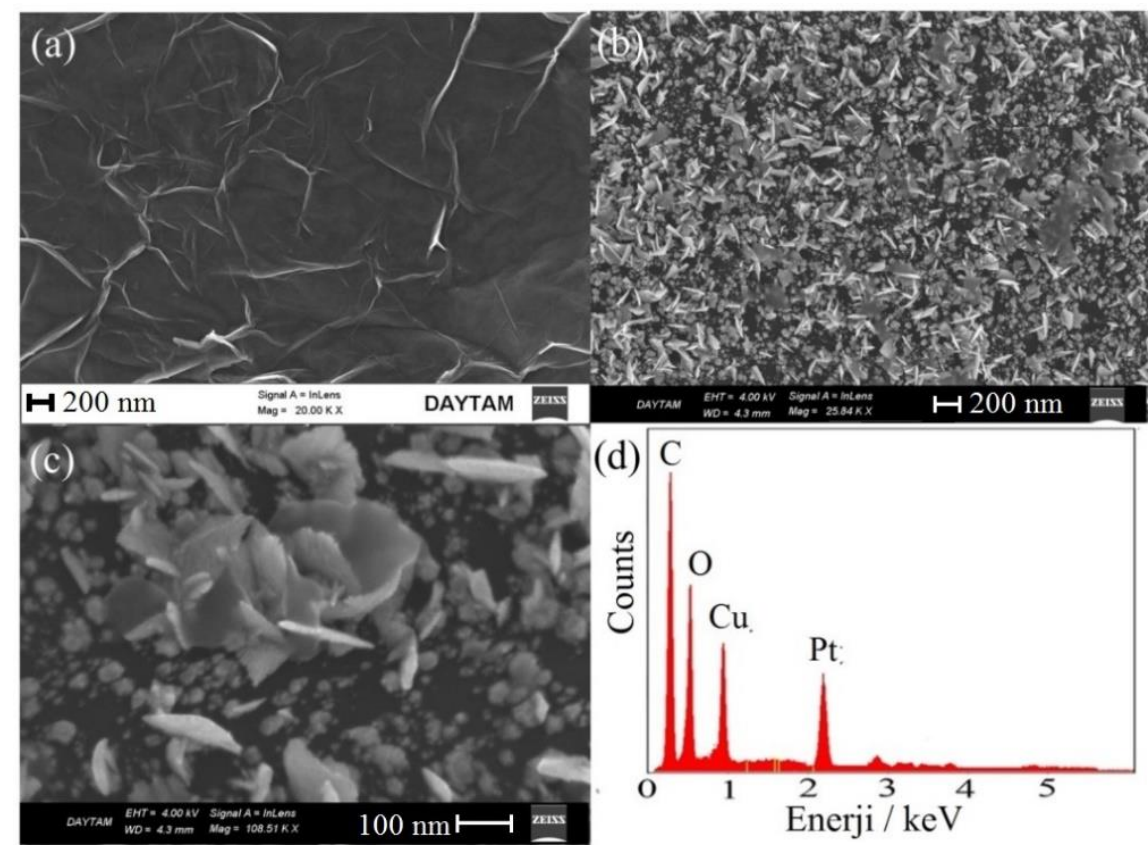

Şekil 3. (a) iGrO kağıda, (b, c) PtCu/iGrO hibrit kağıda ait FESEM görüntüleri. (d) $\mathrm{PtCu} / \mathrm{iGrO}$ hibrit kağıda ait EDX spektrumu

Hazırlanan $\mathrm{PtCu} / \mathrm{iGrO}$ hibrit kağıt elektrodun yapısal karakterizasyonu için elde edilmiş XPS spektrumları Şekil 4'de sunulmuştur. Elde edilen genel XPS spektrumunda kimyasal yapıda $\mathrm{C}, \mathrm{O}, \mathrm{Pt}$ ve $\mathrm{Cu}$ atomlarının varlı̆̆ 1 gözlenmiştir (Şekil 4a). Hazırlanan $\mathrm{PtCu} / \mathrm{iGrO}$ hibrit kağıt elektrotun \%57.03 C, \%22.65 O, \%11.45 Pt ve \%8.87 Cu atomlarını içerdiği belirlenmiştir. $\mathrm{PtCu} / \mathrm{iGrO}$ hibrit kağıda ait spektrumdaki, maksimum pik pozisyonu $283.7 \mathrm{eV}$ olan C1s piki fit edildiğinde, 284, 286 ve $288 \mathrm{eV}$ değerlerinde sirasıyla $\mathrm{C}=\mathrm{C}, \mathrm{C}-\mathrm{O}$ ve $\mathrm{O}-\mathrm{C}=\mathrm{O}$ kimyasal bağ yapılarına karşılık gelen piklerin, maksimum pik pozisyonu $531.9 \mathrm{eV}$ olan O1s piki fit edildiğinde ise $529.4,531$ ve $534.7 \mathrm{eV}$ değerlerinde sirasiyla $\mathrm{C}-\mathrm{O}, \mathrm{O}-\mathrm{H}$ ve $\mathrm{C}=\mathrm{O}$ bağlanmalarına sahip piklerin oluştuğu gözlenmiştir (Şekil 4b,c). PtCu/iGrO hibrit kağıt yapısında bulunan $\mathrm{Pt}$ ve $\mathrm{Cu}$ atomlarına ait yüksek çözünürlüklü XPS spektrumları Şekil 4d, e'de sunulmuştur. 932 ve $950 \mathrm{eV}$ bağlanma enerjilerinde sirasiyla $\mathrm{Cu} 2 \mathrm{p}_{3 / 2}$ ve $\mathrm{Cu} 2 \mathrm{p}_{1 / 2}$ kimyasal yapılarına karşılık gelen piklerin, $\mathrm{Pt}\left(4 \mathrm{f}_{5 / 2}\right)$ ve $\mathrm{Pt}$ $\left(4 \mathrm{f}_{7 / 2}\right)$ kimyasal çevrelerine karş1lık gelen piklerin ise sırasılyla 74.9 ve $71.4 \mathrm{eV}$ değerlerinde oluştuğu gözlenmiştir. Böylece hazırlanan $\mathrm{PtCu} / \mathrm{iGrO}$ hibrit kağıt materyalin önerilen kimyasal bileşimde başarılı bir şekilde hazırlandığı belirlenmiştir.

iGrO ve PtCu/iGrO kağıtların kristal yapılarını belirleyebilmek için XRD tekniği kullanılmıştır (Şekil 5a). iGrO kağıda ait XRD spektrumu incelendiğinde $25.4^{\circ} \mathrm{de}$ grafen yapılarının karakteristik (002) kristal kırınımına karşılık gelen pikin oluştuğu belirlenmiştir (JCPDS kart numarası: 4-0783). PtCu/iGrO hibrit kağıdına ait XRD spektrumu incelendiğinde ise $\mathrm{iGrO}^{\prime}$ ya ait kırınım pikine ilave olarak yaklaşık $40.2^{\circ}, 47.3^{\circ}$, ve $70.2^{\circ} 2 \theta$ değerlerinde $\mathrm{PtCu}$ alaşım nanoyapısının sırasıyla 111, 200 ve 220 kırınımlarına karşıl1k gelen piklerin oluştuğu belirlenmiştir (Pt JCPDS kart numaras1: 04-0802, Cu JCPDS kart numaras1: 85-1326) (Kang vd., 2015). Bu analizler, $\mathrm{PtCu} / \mathrm{iGrO}$ hibrit kağıdın başarılı bir şekilde hazırlandığını desteklemektedir. 

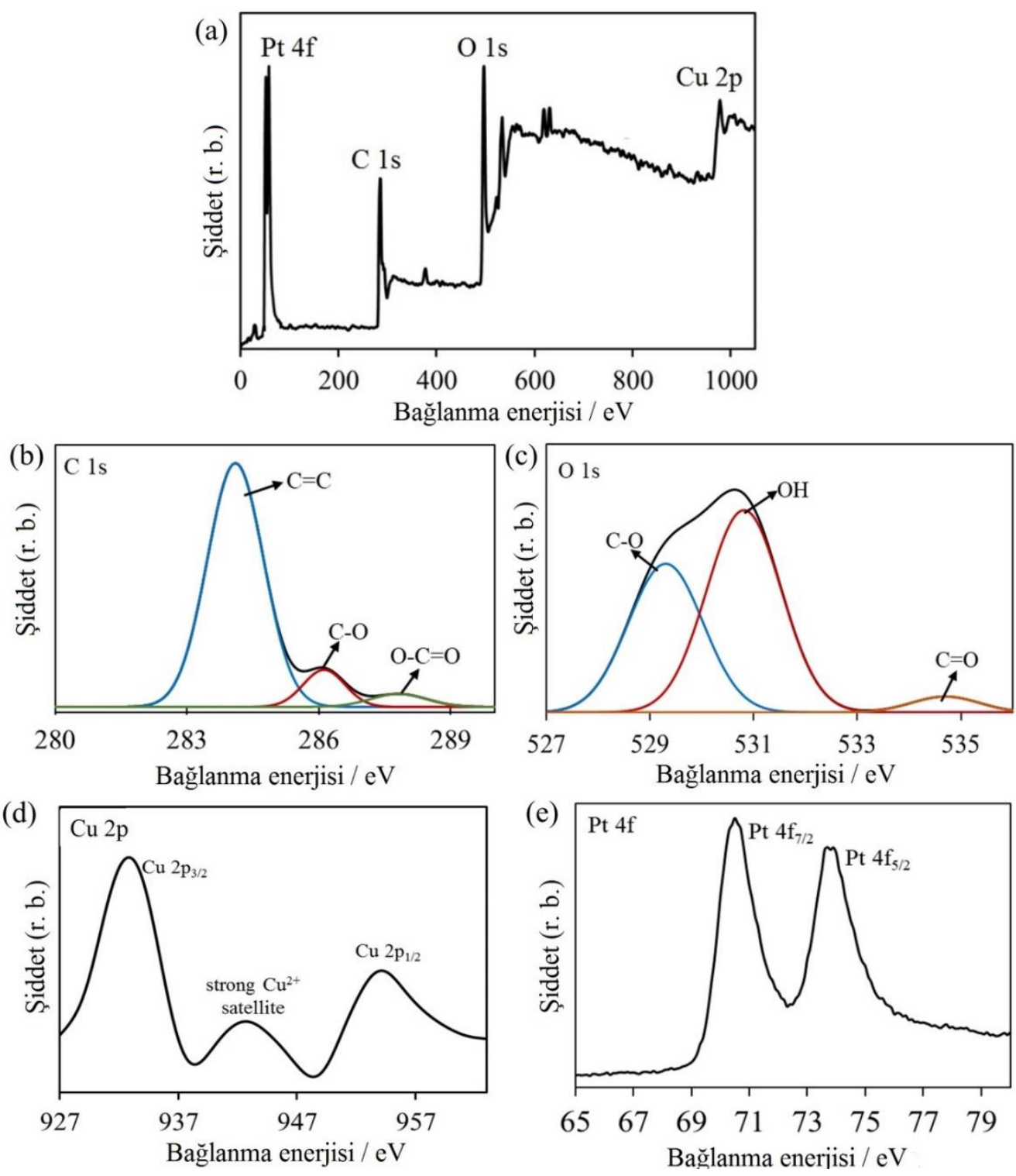

Şekil 4. PtCu/iGrO hibrit kağıdın: (a) genel, (b) C 1s, (c) O 1s, (d) Cu 2p ve (e) Pt 4f atomlarına ait XPS spektrumları

iGrO kağıda ve $\mathrm{PtCu} / \mathrm{iGrO}$ hibrit kağıda ait Raman spektrumları Şekil 5b'de gösterilmiştir. rGO kağıda ait Raman spektrumu incelendiğinde 1610 $\mathrm{cm}^{-1}$ (D band1) dalga sayısinda E2g geometrisine grafenin iki boyutlu hegzagonal $\mathrm{sp}^{2}$ yapisina karşılık gelen pikin, buna ilave olarak yaklaşık $1365 \mathrm{~cm}^{-1}$ (G band1) dalga sayısinda grafen tabakalarının indirgenmelerinden kaynaklı kusurlu yapılara karş1lık gelen pikin oluştuğu gözlenmiştir. Grafen esaslı materyallerde yüzey kusurlarını belirlemek için D ve G bantlarının şiddet oranları kullanılmaktadır (Aksu ve Alanyalıoğlu, 2017). rGO kağıda ve PtCu/iGrO hibrit kağıda ait Raman spektrumlarında $\mathrm{I}_{\mathrm{D}} / \mathrm{I}_{\mathrm{G}}$ oranları sirasiyla 1.62 ve 1.34 olarak belirlenmiştir. Bu durumda, iGrO kağıt elektrot yüzeyinin $\mathrm{PtCu}$ kompozit yapısı ile kaplanması sonucunda, kusurlu bölgelerin kısmen de olsa PtCu yapıları ile kapatıldığı, yani hibrit kă̆ıt elektrotun başarıyla hazırlandığı belirlenmiştir.

Elektrokimyasal çalışmalarda elektrodun ara yüzey özellikleri hakkında bilgi almak için kullanılan en iyi yöntemlerden birisi EIS'dir. Eşit molarda $\left[\mathrm{Fe}(\mathrm{CN})_{6}\right]^{3-14-}$ içeren $0,1 \mathrm{M} \mathrm{KCl}$ çözeltisinde, iGrO ve $\mathrm{PtCu} / \mathrm{iGrO}$ hibrit kağıt elektrotlar için elde edilmiş Nyquist grafikleri Şekil 6'da gösterilmiştir. Nyquist grafikleri iç şekilde verilen elektriksel devreye göre fit edilmiştir. Burada faradayik yük transfer direnci (Rp), oluşan yarım dairenin çapına karşıllı gelmektedir. Çözelti direnci $(\mathrm{Ru})$ ise grafiğin Real Z' eksenini kesim noktasıdır. Sabit faz elemanı (CPE) ise çift tabakanın kapasitansıdır. iGrO ve $\mathrm{PtCu} / \mathrm{iGrO}$ hibrit kağıtlar için elektron transfer dirençleri sırasıyla 126 ve $68 \Omega$ olarak belirlenmiş̧ir. $\mathrm{PtCu} / \mathrm{iGrO}$ hibrit kağıdın elektron transfer direncinin iGrO'ya göre oldukça düşük 
olması, kağıt elektrot yüzeyde bulunan $\mathrm{PtCu}$ alaşım nanokompozit yapısındaki boş $\mathrm{d}$ orbitallerinde elektron kolay hareket edebildiği için elektron transferinin daha kolay gerçekleşebilmesine atfedilmiştir (Topçu ve Dağcı Kıranşan, 2018).
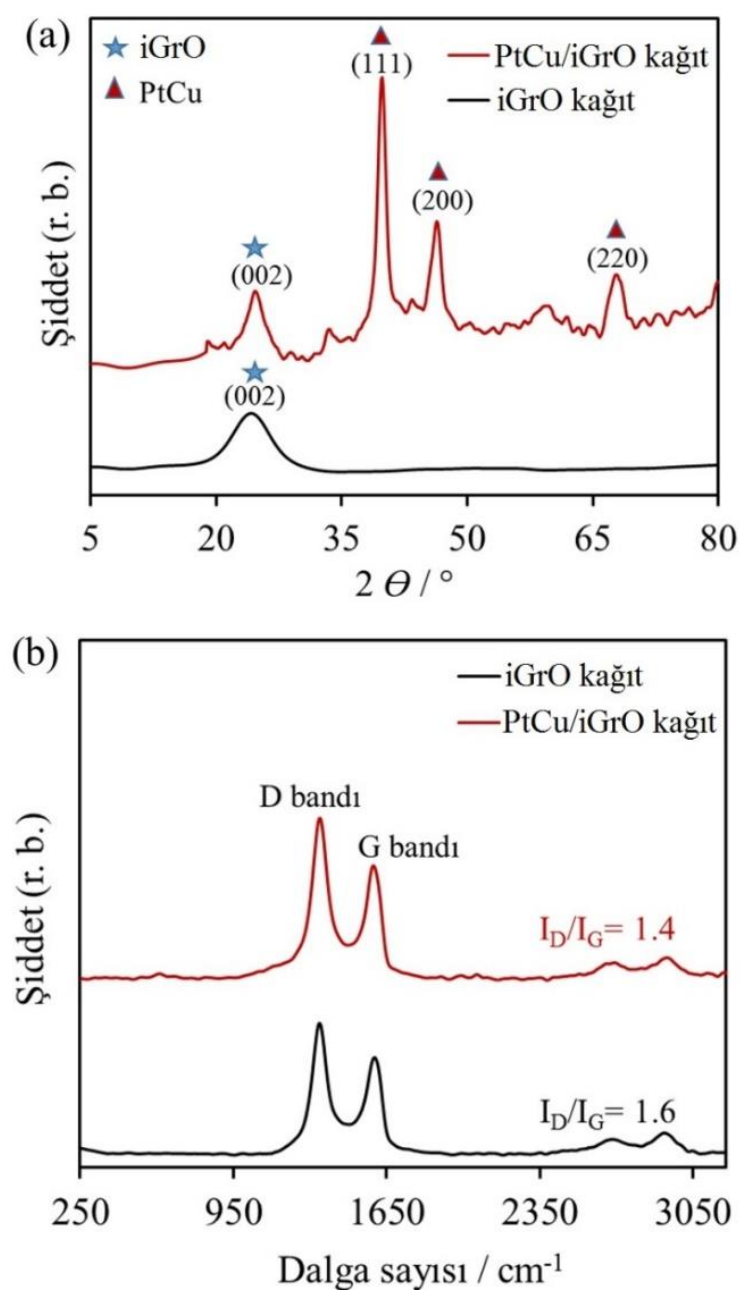

Şekil 5. iGrO kağıda ve $\mathrm{PtCu} / \mathrm{iGrO}$ hibrit kağıda ait; (a) XRD ve (b) Raman spektrumları

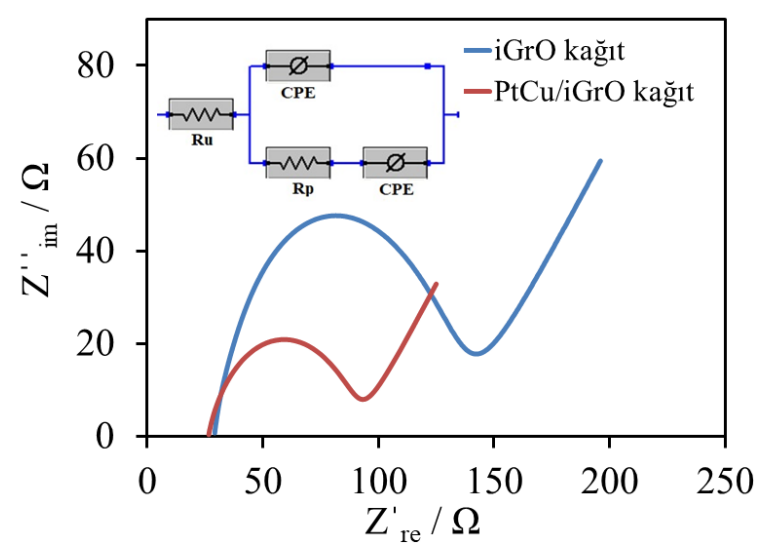

Şekil 6. $0.1 \mathrm{M} \mathrm{KCl}, 1,0 \mathrm{mM} \mathrm{K}_{3} \mathrm{Fe}(\mathrm{CN})_{6}$ ve $1.0 \mathrm{mM}$ $\mathrm{K}_{4} \mathrm{Fe}(\mathrm{CN})_{6}$ içeren çözeltide iGrO kağıt ve NiS/rGO kompozit kağıt elektroda ait Nyquist eğrileri. İç şekil: Kullanılan eşdeğer devre modeli. Frekans değişim: $0.1-10^{5} \mathrm{~Hz}$.

\subsection{PtCu/iGrO Hibrit Kağıt Kullanılarak PNP'nin Elektrokimyasal Tespiti}

Elektrokimyasal tespit çalışmalarında önemli olan kullanılan elektrotların analit için iyi bir katalitik performans sergilemesidir. Katalitik performans, analitin elektrokimyasal reaksiyonunun gerçekleştiği andaki; pik akım yoğunluğunun artması ve potansiyelin düşük potansiyel değerine kaymasıdır. Elektrokimyasal sensör çalışmalarında hazırlanan elektrotların modifiye edilmemiş elektrotlardan daha iyi katalitik performans göstermesi beklenir (Dağc1 ve Alanyalığlu, 2013, 2016). Hazırlanan kağıt elektrotlar üzerinde PNP'nin elektrokimyasal davranışını araştırmak için CV tekniği kullanılmıştır. $500 \mu \mathrm{M}$ PNP içeren $0.1 \mathrm{M} \mathrm{pH} 7.5$ fosfat tampon çözeltisi (PBS) içinde 600 ila $1200 \mathrm{mV}$ arasındaki potansiyel pencerede gerçekleştirilen CV'ler Şekil 7'de sunulmuştur. PNP'nin elektrokimyasal oksidasyonu iGrO elektrot kullanılarak $0.13 \mathrm{~mA} \mathrm{~cm}^{-2}$ akım yoğunluğu ve $1020 \mathrm{mV}$ oksidasyon potansiyelinde, $\mathrm{PtCu} / \mathrm{iGrO}$ hibrit kağıt elektrot üzerinde ise 0.75 $\mathrm{mA} \mathrm{cm}{ }^{-2}$ akım yoğunluğu ve $950 \mathrm{mV}$ oksidasyon potansiyelinde gerçekleştiği belirlenmiştir. Buna göre PNP'nin elektrooksidasyonu için, $\mathrm{PtCu} / \mathrm{iGrO}$ hibrit kağıt elektrodun iGrO elektroda göre daha yüksek katalitik performansa (yüksek akım yoğunluğu ve düşük oksidasyon potansiyeline) sahip olduğu tespit edilmiştir (Şekil 7). CV grafiklerinde gözlenen pik, $1 \mathrm{e}^{-}$ve $1 \mathrm{H}^{+}$kaybeden PNP'nin geri dönüşümsüz oksidasyonuna karş1lık gelmektedir (Saadati vd., 2018) ve meydana gelen elektrokimyasal reaksiyon Şekil 2'de sunulmuştur. Ayrıca, PtCu/iGrO hibrit kağıt elektrot PNP içermeyen çözeltide herhangi bir akım cevabı göstermemiştir. $\mathrm{Bu}$ sonuçlar, $\mathrm{PtCu} / \mathrm{iGrO}$ hibrit kağıt elektrot yüzeyinde bulunan $\mathrm{PtCu}$ alaşım nanokompozit yapıların, sahip oldukları keskin kenarlı düzlemsel şekillerinden dolayı, elektroaktif yüzey alanını artırarak $\mathrm{PtCu} / \mathrm{iGrO}$ hibrit kağıt elektrodun PNP için daha yüksek elektrokatalitik davranış sergilemesini sağlamış ve böylece PNP'nin, esnek PtCu/iGrO hibrit elektrot üzerinde yüksek duyarlılıkla belirlenebileceği tespit edilmiştir.

Analit çözeltisinin $\mathrm{pH}$ değeri, katalitik davranışı etkileyen ana faktörlerden biridir. $\mathrm{Bu}$ nedenle PNP'nin PtCu/iGrO hibrit kağıt elektrot üzerindeki elektrokatalitik performans 1 farklı $\mathrm{pH}$ değerlerine sahip çözeltilerde test edilmiş ve ilgili CV'ler Şekil 8a,b'de sunulmuştur. Analit çözeltisinin $\mathrm{pH}$ değerinin artmasıyla, çözeltideki $\mathrm{H}^{+}$iyonlarının azalmasından dolayı elektrokimyasal etkinliğin $\operatorname{artt1} \breve{g} 1$, ancak bazik pH değerlerinde ise PNP'nin elektrokimyasal aktivitesini kaybetmeye 
başlayacağı için katalitik aktivitenin azaldığ1 gözlenmiştir. PtCu/iGrO elektrodu, PNP için 0.72 $\mathrm{mA} \mathrm{cm}{ }^{-2}$ pik akım yoğunluğu ile $7.5 \mathrm{pH}$ değerinde en yüksek performansı göstermiştir. Buna göre, yapilan elektrokimyasal deneylerde analit çözeltisinin $\mathrm{pH}$ değeri 7,5 olarak hazırlanmıştır.

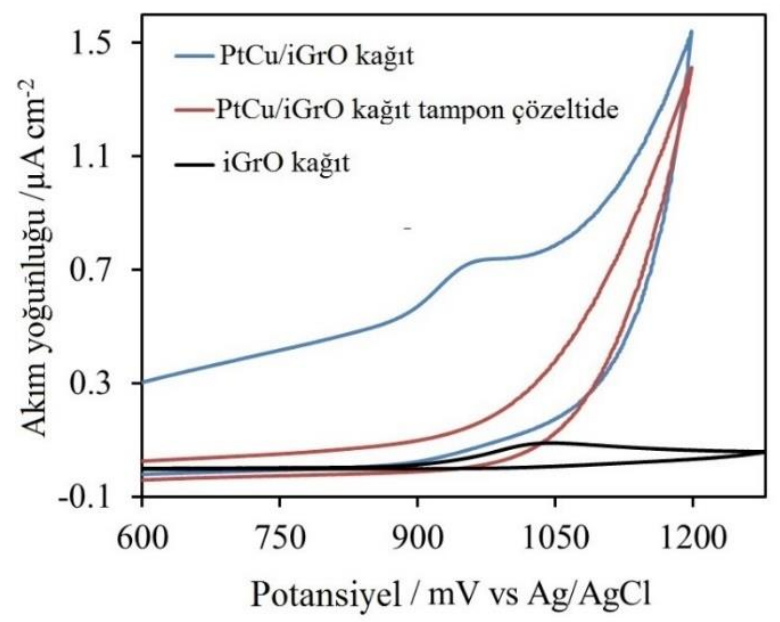

Şekil 7. $500 \mu \mathrm{M}$ PNP içeren 0.1 M PBS (pH 7.5) içinde iGrO (siyah) ve $\mathrm{PtCu} / \mathrm{iGrO}$ (mavi) hibrit kağıt elektrodun CV grafikleri ve PNP içermeyen 0.1 M PBS (pH 7.5) içinde PtCu/iGrO (kırmızı) hibrit kağıt elektrodun CV grafiği. Tarama hızı: 50 $\mathrm{mV} \mathrm{s}^{-1}$

iGrO kağıt yüzeyinde biriktirilen $\mathrm{PtCu}$ alaşım nanokompozit yapısının kalınlığı, elektrodun elektrokatalitik aktivitesini etkileyen bir başka parametredir. iGrO kağıt yüzeyi üzerinde farklı çevrim sayılarında elde edilen $\mathrm{PtCu} / \mathrm{iGrO}$ hibrit kağıt sensörlerin PNP için elektrokatalitik performansı araştırılmıştır (Şekil 8a,b). iGrO kağıt elektrot üzerinde, 0 ila $-1200 \mathrm{mV}$ potansiyel penceresinde 18 döngü ile hazırlanan $\mathrm{PtCu}$ filminin PNP'nin tayini için en yüksek katalitik aktivite sergilediği gözlenmiştir. (Şekil 9). Yüzeye kaplanan keskin kenarlı, düzlemsel tabakalı yapılardan dolayı elektrotun yüzey alanının artması nedeniyle döngü sayısı arttıkça elektrokatalitik aktivite de artmıştır. Bununla birlikte, döngü sayısı 18'in üzerine çıktığında, $\mathrm{PtCu}$ alaşım nanoyapısı elektrot yüzeyinde düzensiz olarak büyümeye başlayacağ 1 ve fazla metal birikiminden dolayı aktivitesinin düşeceği ve böylece elektrokimyasal cevabın da azalacağı anlaşılmaktadır. Bu nedenle 18 döngü, $\mathrm{PtCu} / \mathrm{iGrO}$ hibrit kağıt sensör üzerinde PNP'nin en iyi elektrokatalitik performansı için optimize edilmiştir.
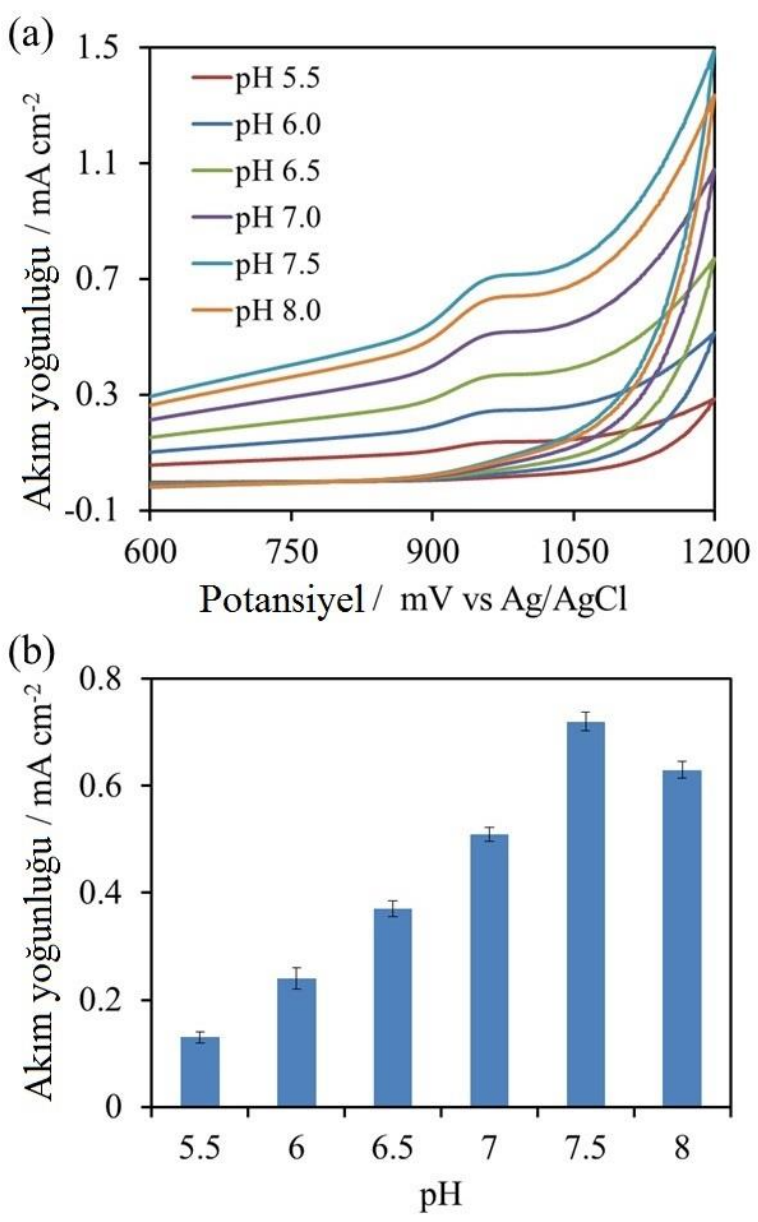

Şekil 8. (a) $200 \mu \mathrm{M}$ PNP içeren farklı pH'ya sahip PBS içindeki PtCu/iGrO hibrit kağıt elektrodun CV'leri. Tarama hızı: $50 \mathrm{mV} \mathrm{s}^{-1}$. (b) $\mathrm{PtCu} / \mathrm{iGrO}$ hibrit kağıt üzerinde PNP'nin elektrokimyasal tespiti için farklı tampon çözeltilerindeki akım yoğunluk değerleri.

Amperometrik deneyler, 18 döngü ile hazırlanan $\mathrm{PtCu} / \mathrm{iGrO}$ hibrit kağıt elektrot üzerinde, karıştırılan 0.1 M PBS (pH: 7.5) çözeltisi içinde $950 \mathrm{mV}$ sabit potansiyelde gerçekleştirilmiştir. Art arda PNP ilavesiyle elde edilen $\mathrm{PtCu} / \mathrm{iGrO}$ hibrit kağıt elektrodun amperometrik yanıtı Şekil 10a'da sunulmuştur. PNP'nin 0.1 M PBS'ye (pH: 7.5) ilave edilmesinden sonra, anodik akım yoğunluğunun kararlı bir değere ulaşmak için dik bir şekilde arttığ gözlenmiştir. Elektrot, neredeyse 5 saniyeden daha az bir sürede sabit bir akım yoğunluğu sergilemiş ve bu durum elektrokatalitik yanıtın çok kısa bir sürede gerçekleştiğini göstermiştir. Şekil 10a'dan elde edilen kalibrasyon eğrisi Şekil $10 b$ 'de sunulmuştur. PtCu/iGrO hibrit kağıt elektrodun PNP'nin katalitik oksidasyonu için 0.08-760 $\mu \mathrm{M}$ aralığında doğrusal bir yanıta sahip olduğu belirlenmiştir. Kalibrasyon eğrisi için denklem, 0.9995 korelasyon katsayısı ile $\mathrm{j}(\mathrm{mA}$ $\left.\mathrm{cm}^{-2}\right)=0.0016 \mathrm{C}_{\mathrm{PNP}}(\mu \mathrm{M})+0.00008$ olarak hesaplanmıştır. Elde edilen kalibrasyon grafiğginden dedeksiyon limiti $0.022 \mu \mathrm{M}$ ve 
duyarl111k $0.0016 \mathrm{~mA} \mu \mathrm{M} \mathrm{cm}^{-2}(\mathrm{~S} / \mathrm{N}=3)$ olarak tespit edilmiştir.
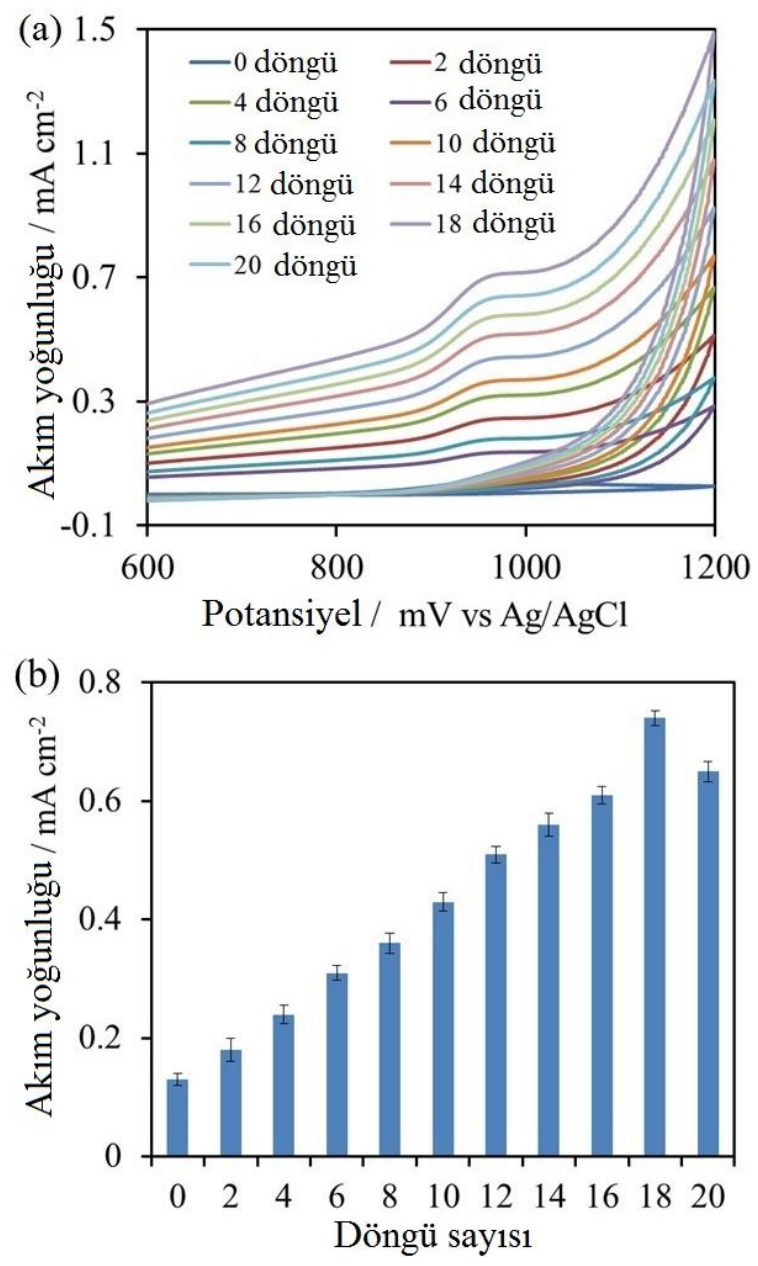

Şekil 9. (a) $0,2,4,8,10,12,14,16,18$ ve 20 döngü sayılarında hazırlanan $\mathrm{PtCu} / \mathrm{iGrO}$ hibrit kağıt elektrot üzerinde $200 \mu \mathrm{M}$ PNP CV'leri. Tarama hızı: $50 \mathrm{mV} \mathrm{s}^{-1}$. (b) Farklı döngü sayılarında hazırlanan $\mathrm{PtCu} / \mathrm{iGrO}$ hibrit kağıt elektrodunda PNP'nin elektrokimyasal tespiti için akım yoğunluk değerleri

Elektrokimyasal sensör çalışmalarında, hazırlanan sensörün; iyi bir katalitik etkiye sahip olmasının yanı sıra, mekanik olarak dayanıklı olması, ardışık olarak kullanılabilmesi, atmosferik koşullarında uzun süre bozulmadan kalabilmesi ve aynı yöntemle farklı zamanlarda hazırlanan sensörlerin analit için benzer akım cevabı vermesi beklenmektedir.

PNP'nin elektrokimyasal tayini için $\mathrm{PtCu} / \mathrm{iGrO}$ hibrit kağıt sensörün fiziksel ve mekanik dayanıklılığı araştırılmıştır (Dağc1 Kıranşan, 2019; Dağc1 Kuranşan and Topçu, 2019). Bu kapsamda esnek $\mathrm{PtCu} / \mathrm{iGrO}$ hibrit kağıt sensör aynı gün içerisinde art arda PNP'nin elektrokatalitik tayini için kullanılmış ve akım yoğunluğu değerlerinde meydana gelen değişim değerlendirilmiştir.
PNP'nin elektrokatalitik tayini için 20, 40 ve $90 \mathrm{kez}$ kullanımlar sonucunda bile, ilk akım yoğunluğu değerinin sirasiyla $\% 98, \% 95$ ve $\% 88$ oranlarında elde edildiği belirlenmiştir (Şekil 11a). Böylece $\mathrm{PtCu} / \mathrm{iGrO}$ hibrit kağıt sensörün elektroaktif yüzey yapısının, ardı ardına gerçekleştiren elektrokimyasal işlemler sırasında bozulmadan kalabildiği ve oldukça stabil olduğu sonucuna varılmıştır. $\mathrm{Bu}$ sonuçlar $\mathrm{PtCu} / \mathrm{iGrO}$ hibrit kağıt sensörün PNP'nin elektrokatalitik tayini için yüksek tekrar-tekrar kullanılabilme özelliğine sahip olduğunu göstermiştir.
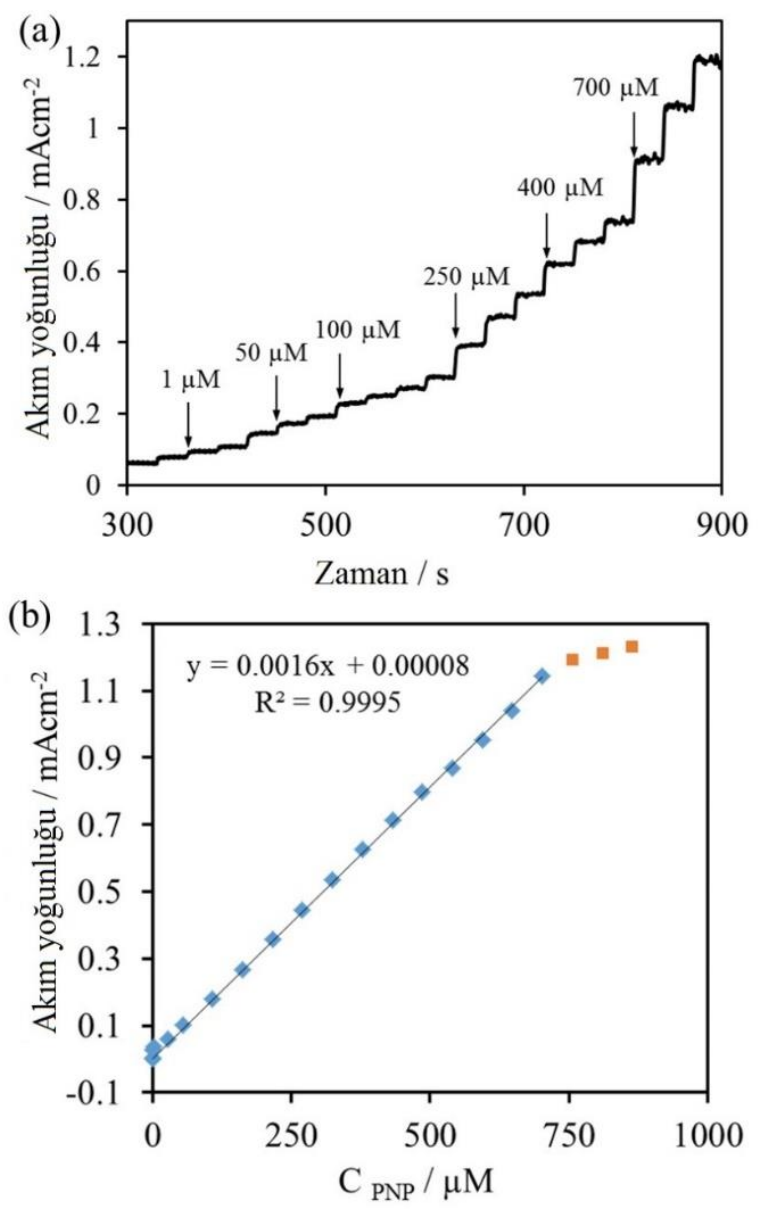

Şekil 10. (a) 1000 rpm'de karıştırılan $10 \mathrm{~mL} 0.1 \mathrm{M}$ PBS'ye (pH 7.5) 950 mV'de ardarda PNP ilavesi sonucu $\mathrm{PtCu} / \mathrm{iGrO}$ hibrit kağıt elektrodun amperometrik yanıtı. (b) PNP'nin PtCu/iGrO hibrit kağıt elektrot kullanılarak elektrokimyasal belirlenmesi için kalibrasyon eğrisi

PNP'nin elektrokatalitik tayini için esnek $\mathrm{PtCu} / \mathrm{iGrO}$ hibrit kağıt sensörün yeniden üretilebilirliğini test etmek için, aynı deney koşulları altında ve aynı yöntem kullanılarak 4 farklı kağıt sensör hazırlanmıştır. Hazırlanan $\mathrm{PtCu} / \mathrm{iGrO}$ hibrit kağıt sensörler PNP'nin elektrokatalitik tayini için kullanılmış ve elde edilen sonuçlar Şekil 11b'de sunulmuştur. 4 farklı $\mathrm{PtCu} / \mathrm{iGrO}$ hibrit kağıt sensör kullanılarak elde 
edilen akım yoğunluğu değerleri değerlendirildiğinde, standart sapmanın 0.05 olduğu belirlenmiştir. $\mathrm{PtCu} / \mathrm{iGrO}$ hibrit kağıt sensörlerin PNP'nin elektrokatalitik tayini oldukça yakın akım cevapları verdikleri gözlenmiş ve böylece önerilen kağıt hibrit sensörün yeniden üretilebilir olduğu sonucuna varılmıştır.
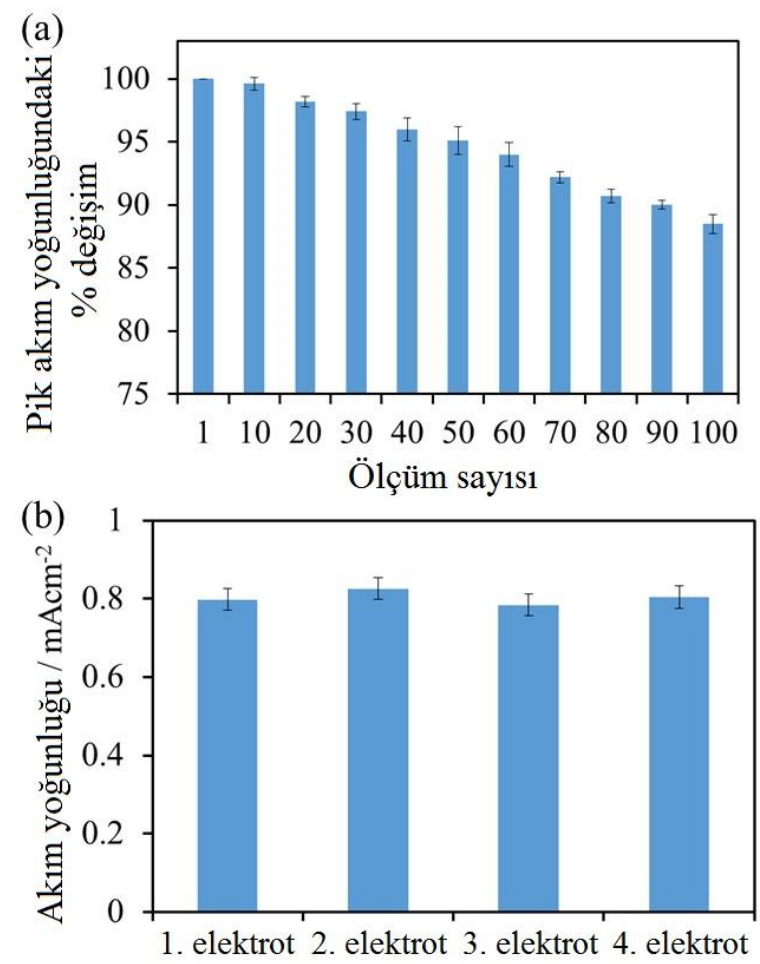

Şekil 11. PNP'nin amperometrik tayini için $\mathrm{PtCu} / \mathrm{iGrO}$ hibrit kağıt sensörün (a) tekrar kullanılabilirliği ve (b) üretilebilirliği

PNP tayininde kullanılan $\mathrm{PtCu} / \mathrm{iGrO}$ hibrit kağıt sensörün depolanma stabilitesini test etmek için, kağıt sensör 2,15 ve 20 gün atmosfer koşullarında (0.96 atm basınç, $20^{\circ} \mathrm{C}$ sıcaklık, ve güneş 1şı̆̆ı ile aydınlatılan ortam) bekletildikten sonra, elektrokimyasal cevabı incelenmiş ve başlangıç akım değerleri sırasıyla \%98, \%94 ve \%89 olarak tespit edilmiştir (Şekil 12a). Başlangıç akım yoğunluğu değerinin 20 gün sonunda $\% 11$ değiştiği gözlenmiş ve böylece hazırlanan hibrit kağıt sensörün yüksek bir depolanma stabilitesine sahip olduğu tespit edilmiştir. $\mathrm{PtCu} / \mathrm{iGrO}$ hibrit kağıt sensörün esnekliği, hibrit kağıt sensörün ard1ardına bükülüp açılması sonucu, elektrokimyasal cevabında meydana gelen değişme ile test edilmiş. PNP'nin bükülmüş elektrot üzerindeki elektrokimyasal aktivitesi Şekil 12b'de gösterilmiştir. Kağıt elektrotun başlangıç akım yanıtının, 40 ve $90 \mathrm{kez} 180^{\circ}$ içe katlanmasından sonra sirasıyla $\% 4$ ve $\% 8$ azaldığ $\mathrm{PtCu} / \mathrm{iGrO}$ hibrit kağıt sensörün $180^{\circ}$ içe doğru 90 kez büküldükten sonra bile fiziksel yapısını değiştirmediği gözlenmiştir. Bu sonuçlar, müstakil $\mathrm{PtCu} / \mathrm{iGrO}$ hibrit kağıdın esnek sensör uygulamaları için uygun olduğunu göstermiştir.
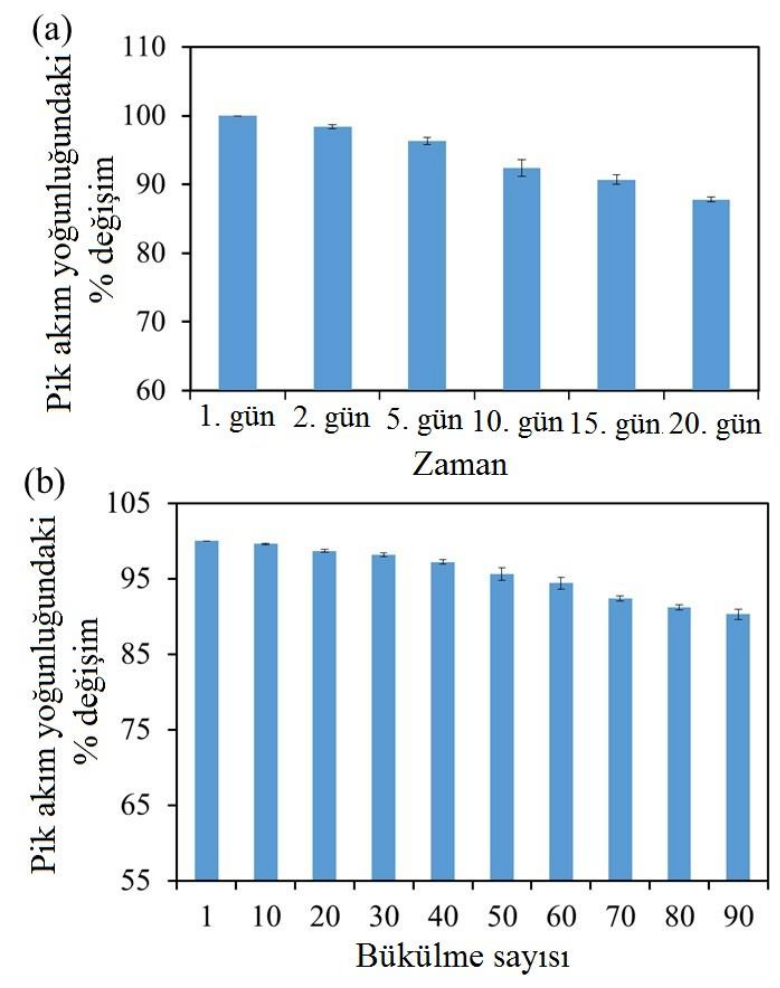

Şekil 12. PNP'nin amperometrik tayini için $\mathrm{PtCu} / \mathrm{iGrO}$ hibrit kağıt sensörün (a) zamana bağl1 kararlılığı ve (b) esnekliği

Elektrokimyasal sensör çalışmalarında, analit türleri ile aynı ortamda bulunabilecek diğer iyonların veya bileşiklerin girişim yapabilmesi mümkündür. Hazırlanan sensörün, diğer girişim yapan türler içerisinden, analite seçici olarak yanıt vermesi beklenmektedir (Song vd., 2015). Esnek $\mathrm{PtCu} / \mathrm{iGrO}$ hibrit kağıt sensörün PNP tayini için girişim yapan türlere göre seçiciliğini araştırmak için amperometrik çalışma gerçekleştirilmiştir. PNP ve girişim yapan türlerin $0.1 \mathrm{M}$ PBS'ye $(\mathrm{pH}$ 7.5) art arda eklenmesi ile elde edilen $\mathrm{PtCu} / \mathrm{iGrO}$ hibrit kağıt sensörün amperometrik yanıtı Şekil 13'de sunulmuştur. Çözeltiye PNP'nin konsantrasyonundan 20 kat daha fazla konsantrasyonda olan iyonlar ve PNP ile ayn konsantrasyonda folik asit, glikoz ve üre eklendiğinde hiçbir akım cevabı gözlenmemiştir (Dağc1 Kıranşan, 2019). Buna karşılık, elde edilen amperometrik sonuçlar, PNP'nin elektrokimyasal oksidasyonuna katekol, ürik asit ve fenolün girişim yaptığını göstermiştir. $\mathrm{Bu}$ üç maddenin de elekrokimyasal oksidasyon potansiyelleri PNP'den daha düşük olduğu için, PNP'nin elekrokimyasal oksidasyona uğradığ 1 potansiyelde girişim yapmaları beklenen bir durumdur (Dağc1 Kıranşan ve Topçu, 2018). Bu sonuçlar doğrultusunda, esnek 
$\mathrm{PtCu} / \mathrm{iGrO}$ hibrit kağıt sensörün, girişim yapan türler içeren çözeltide bile PNP'nin belirlenmesi için kısmen de olsa iyi bir seçiciliğe ve hassasiyete sahip olduğu sonucuna varılmıştır.

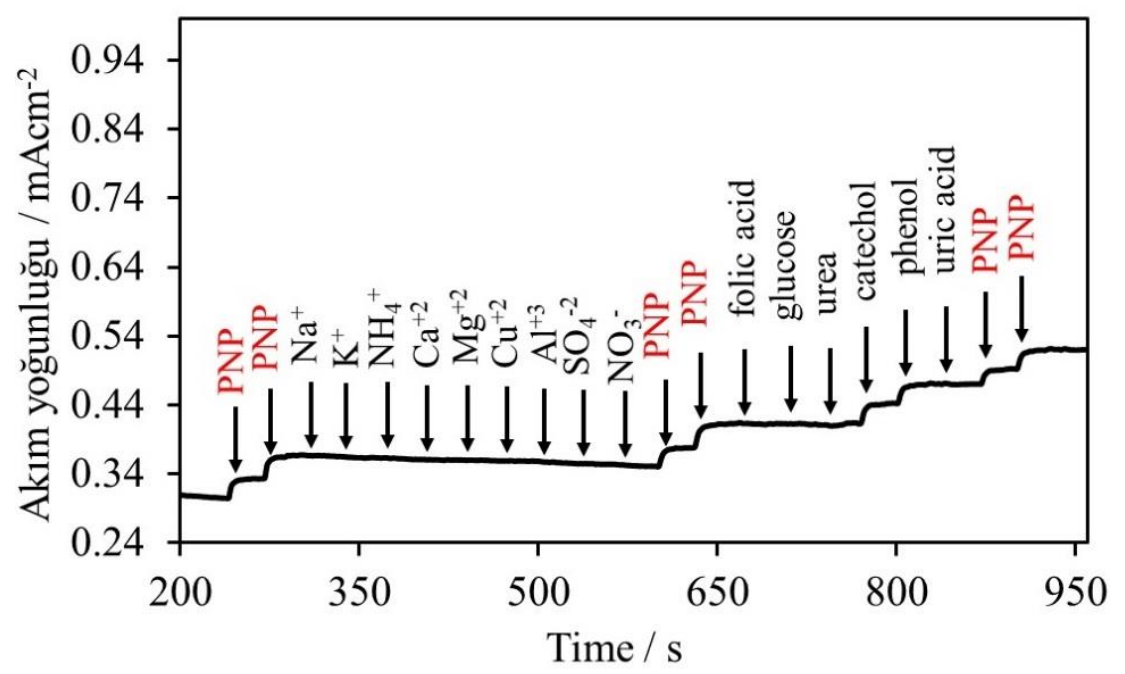

Şekil 13. 0.1 M PBS'ye ( $\mathrm{pH}$ 7.5) düzenli aralıklarla (50 s) $\mathrm{Na}^{+}, \mathrm{K}^{+}, \mathrm{NH}_{4}^{+}, \mathrm{Ca}^{+2}, \mathrm{Mg}^{+2}, \mathrm{Cu}^{+2}, \mathrm{Al}^{+3}, \mathrm{SO}_{4}^{-}$ ${ }_{2}^{2}, \mathrm{NO}_{3}$, folik asit, glikoz, üre, katekol, fenol, ürik asit ve PNP'nin ard arda eklenmesiyle PtCu/iGrO hibrit kağıt sensörde elde edilen amperometrik i - t eğrisi . Uygulanan potansiyel $950 \mathrm{mV}$.

$\mathrm{PtCu} / \mathrm{iGrO}$ hibrit kağıt sensörü ile PNP'nin amperometrik tayini için gerçek örnek olarak musluk suyu kullanılmıştır. Standart ekleme yöntemi kullanılarak analiz edilen tüm numunelerin sonuçları Tablo l'de sunulmuştur (Her bir numunenin analizi dört kere tekrar edilmiş ve bu dört tekrarın ortalaması sunulmuştur). Oldukça düşük standart sapma aralı̆̆ında $(0.19-0.33)$ ve oldukça yüksek geri kazanımlar (\% 93.1 - 99.6) ile PNP'nin tayin edildiği belirlenmiștir. Elde edilen yüksek geri kazanımlar, müstakil ve esnek $\mathrm{PtCu} / \mathrm{iGrO}$ hibrit kağıt sensörün ticari numunelerde PNP'nin amperometrik tayininde etkili bir şekilde kullanılabileceğini göstermiştir.

Tablo 1. Gerçek musluk suyu örneklerinde PNP tayini için PtCu/iGrO hibrit kağıt sensörün performans1

\begin{tabular}{cccc}
\hline Örnek & İlave edilen $(\boldsymbol{\mu M})^{\mathbf{a}}$ & ${\text { Tayin edilen }(\boldsymbol{\mu M})^{\mathbf{a}}}$ & Geri kazanım $(\%)$ \\
\hline Tap water 1 & 10 & $9.3 \pm 0.33$ & 93.1 \\
2 & 30 & $28.3 \pm 0.24$ & 94.3 \\
3 & 50 & $48.6 \pm 0.25$ & 97.2 \\
4 & 70 & $69.7 \pm 0.29$ & 99.6 \\
5 & 150 & $149.3 \pm 0.19$ & 99.5 \\
\hline${ }^{a}$ Dört analiz sonucunun ortalamas1. & & \\
\hline
\end{tabular}

Esnek ve müstakil $\mathrm{PtCu} / \mathrm{iGrO}$ hibrit kağıt elektrot kullanılarak PNP'nin tayini şu ana kadar incelenmemiştir. Tablo 2'de PNP'nin amperometrik tayini için önerilen sensörün performans1, daha önce yayınlanan çalışmalarla karş1laştırılmıştır. Buna göre, PNP'nin amperometrik tayini için $\mathrm{PtCu} / \mathrm{iGrO}$ hibrit kağıt sensör geniş bir doğrusal aralık göstermiştir. Bununla birlikte, hazırlanan hibrit kağıt elektrot iGrO'dan oluştuğu için, diğer metal destekli elektrotlara (camsı karbon elektrot (GCE), yüzey bask1lı elektrot (SPE), indiyum kalay oksit kaplı cam elektrot (ITO) gibi), k1yasla elektrik iletkenliğinin daha düşük olduğu açıktır. Bu nedenle, yüzeyi $\mathrm{PtCu}$ yapısı ile modifiye edilmiş ve elektrokimyasal aktivitesi arttırılmış olmasına rağmen, dedeksiyon limit değeri çok düşük bulunmamıştır. $\mathrm{PtCu} / \mathrm{iGrO}$ hibrit kağıt sensörü esneklik, kararlılık ve çift taraflı ve müstakil olması gibi özelliklerinden dolayı diğer elektrotlardan ayrılır ve bu özelliklerinden dolayı birçok potansiyel uygulamalarda kullanılabilir. Tablo 2 'de sunulan modifiye edilmiş sensörler, GCE gibi katı destek malzemeleri kullanılarak tasarlanmıştır. $\mathrm{Bu}$ çalışmanın en önemli farkı, kimyasal olarak kararl1, müstakil ve çift taraflı bir elektrot olan esnek $\mathrm{PtCu} / \mathrm{iGrO}$ hibrit kağıt elektrot üzerinde PNP tespitinin başarılı bir şekilde gerçekleştirilmiş olmasıdır. Elektrot yüzeyindeki keskin kenarlı, düzlemsel tabakalı yapıya sahip $\mathrm{PtCu}$ alașım nanoyapıları, PNP'nin tayininde $\mathrm{PtCu} / \mathrm{iGrO}$ hibrit kağıt elektrodun elektrokatalitik aktivitesini 
artırmıştır. Sonuç olarak $\mathrm{PtCu} / \mathrm{iGrO}$ hibrit kağıt sensörün, yüksek kararlılık ve esneklik gibi mükemmel özellikleri ile PNP'nin kantitatif tayini için in vivo uygulamalarda kullanılabileceği belirlenmiştir.

Tablo 2. PNP tayini için esnek PtCu/iGrO hibrit kağıt sensörün diğer çalışmalarla karşılaştırılması

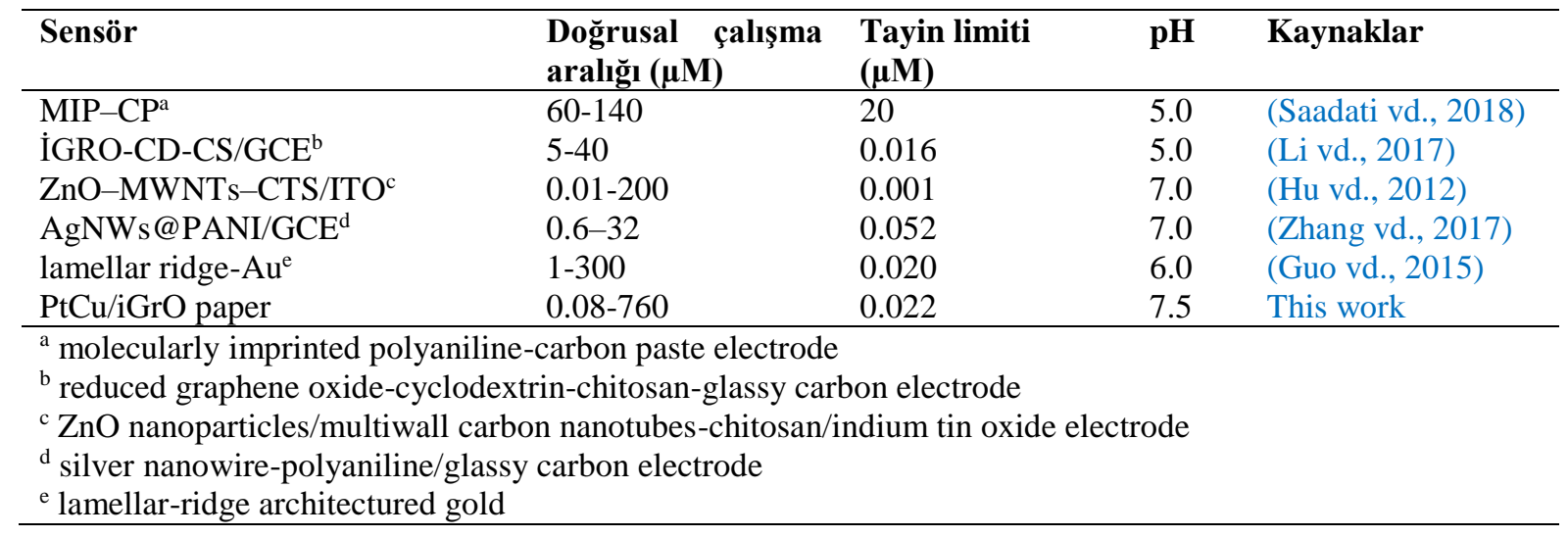

\section{Sonuçlar}

Bu çalışmada, iGrO kağıt yüzeyinin $\mathrm{PtCu}$ alaşım nanoyapıları ile basit bir elektrokimyasal teknik kullanılarak kaplanması suretiyle esnek, müstakil ve $2 \mathrm{D} \mathrm{PtCu} / \mathrm{iGrO}$ hibrit kağıt elektrot hazırlanmıştır. iGrO kağıt yüzeyi üzerinde sentezlenen $\mathrm{PtCu}$ alaşım nanoyapıları, sahip olduğu keskin kenarlı düzlemsel tabaka şeklindeki yüzey morfolojisinden dolayı, kağıt elektrodun aktif yüzey alanını arttırarak $\mathrm{PtCu} / \mathrm{iGrO}$ hibrit kağıt elektrodun yüksek elektrokatalitik aktivite göstermesini sağlamıştır. Esnek $\mathrm{PtCu} / \mathrm{iGrO}$ hibrit kağıt elektrot, PNP'nin elektrokimyasal tayini için kullanılmış ve nispeten yüksek hassasiyet $(0.0016$ $\left.\mathrm{mAcm}^{-2} \mu \mathrm{M}^{-1}\right)$, geniş doğrusal aralık $(0.08-760$ $\mu \mathrm{M})$ ve düşük tespit limiti $(0.022 \mu \mathrm{M})$ göstermiştir. Esnek $\mathrm{PtCu} / \mathrm{iGrO}$ hibrit kağıt sensörü, PNP analizi için gerçek su örneklerinde yüksek hassasiyet göstermiştir. $\mathrm{Bu}$ müstakil sensörün, yüksek esneklik ve dayanıklılığa sahip olması nedeniyle PNP'nin belirlenmesi için esnek algilama uygulamalarında iyi bir aday olacağı belirlenmiştir.

\section{Kaynaklar}

Aksu, Z. and Alanyalığlu, M. (2017). Fabrication of free-standing reduced graphene oxide composite papers doped with different dyes and comparison of their electrochemical performance for electrocatalytical oxidation of nitrite. Electrochimica Acta, 258, 1376-1386. https://doi.org/10.1016/j.electacta.2017.11.197.

Chi, K., Zhang, Z., Xi, J., Huang, Y., Xiao, F., Wang, S. and Liu, Y., (2014). freestanding graphene paper supported three-dimensional porous graphenepolyaniline nanocomposite synthesized by inkjet printing and in flexible all-solid-state supercapacitor. ACS Applied Material Interfaces,
6 ,

16312-16319.

https://doi.org/10.1021/am504539k

Dagci, K. and Alanyalıoglu, M. (2013). Electrochemical preparation of polymeric films of pyronin $y$ and its eectrolcatalytic properties for amperometric detection of nitrite. Journal of Electroanalytical Chemistry, 711 17-24. https://doi.org/10.1016/j.jelechem.2013.10.016

Dagci, K. and Alanyalıoglu, M. (2016). Preparation of free-standing and flexible graphene/Ag nanoparticles/poly(pyronin y) hybrid paper electrode for amperometric determination of nitrite. ACS Applied Material Interfaces, 8, 2713-2722.

https://doi.org/10.1021/acsami.5b10973

Dağcı Kıranşan, K., Topçu, E. and Alanyalıŏglu, M. (2017). Surface-confined electropolymerization of pyronin $\mathrm{y}$ in the graphene composite paper structure for the amperometric determination of dopamine. Journal of Applied Polymer Science, 134, $45139 \quad$ (1-10). https://doi.org/10.1002/app.45139

Dağcı Kıranşan, K., Aksoy, M. and Topçu, E. (2018). Flexible and freestanding catalase$\mathrm{Fe} 3 \mathrm{O} 4 /$ reduced graphene oxide paper: enzymatic hydrogen peroxide sensor applications. Materials Research Bulletin, 106, 57-65. https://doi.org/10.1016/j.materresbull.2018.05.0 32

Dağcı Kıranşan, K. and Topçu, E. (2018). Free-standing and flexible MoS2/GrO paper electrode for amperometric detection of folic acid. Electroanalysis, $\quad 30, \quad 810-818$. https://doi.org/10.1002/elan.201700778

Dağc1 Kıranşan, K. (2019). Preparation and characterization of highly flexible, free-standing, three-dimensional and rough $\mathrm{NiMOF} / \mathrm{rGO}$ 
composite paper electrode for determination of catechol. ChemistrySelect, 4, 6488-6495. https://doi.org/10.1002/slct.201900974

Dağcı Kıranşan, K. and Topçu, E. (2019). Graphene paper with sharp-edged nanorods of Fe-CuMOF as an excellent electrode for the simultaneous detection of catechol and resorcinol. Electroanalysis, $\quad 31, \quad 2518-2529$. https://doi.org/10.1002/elan.201900352

Dağcı Kıranşan, K. and Topçu, E. (2020). Conducting polymer-reduced graphene oxide sponge electrode for electrochemical detection based on DNA hybridization. ACS Applied Nano Materials, 3, 5449-5462. https://doi.org/10.1021/acsanm.0c00782

Ge, C., Li, H., Li, M., Li, C., Wu, X. and Yang, B. (2015). Synthesis of a $\mathrm{ZnO}$ nanorod/CVD graphene composite for simultaneous sensing of dihydroxybenzene 1somers. Carbon, 95, 1-9. https://doi.org/10.1016/j.carbon.2015.08.006

Guo, X., Zhou, H., Fan, T. and Zhang, D. (2015). electrochemical detection of p-nitrophenol on surface 1mprinted gold with lamellar-ridge architecture. Sensors and Actuators B: Chemical, 220 , 33-39. https://doi.org/10.1016/j.snb.2015.05.042

Hu,Y.F., Zhang, Z.H., Bin Zhang, H., Luo, L.J. and Yao, S.Z. (2012). sensitive and selective imprinted electrochemical sensor for p-nitrophenol based on $\mathrm{ZnO}$ nanoparticles/carbon nanotubes doped chitosan film. Thin Solid Films, 520, 5314-5321. https://doi.org/10.1016/j.tsf.2011.11.083

Kang, W., Li, R., Wei, D., Xu, S., Wei, S. and Li, H. (2015). CTAB-reduced synthesis of urchin-like $\mathrm{Pt}-\mathrm{Cu}$ alloy nanostructures and catalysis study towards the methanol oxidation reaction. RSC Advances, $\quad$ 5, 94210-94215. https://doi.org/10.1039/C5RA20464J

Li, C., Wu, Z., Yang, H., Deng, L. and Chen, X. (2017). reduced graphene oxide-cyclodextrin-chitosan electrochemical sensor: Effective and simultaneous determination of $\mathrm{o}-$ and $\mathrm{p}$ nitrophenols. Sensors and Actuators B: Chemical, 251, 446-454. https://doi.org/10.1016/j.snb.2017.05.059

Liu, N., Cai, X., Zhang, Q., Lei, Y. and Chan-Park, M.B. (2008). Real-time nitrophenol detection using single-walled carbon nanotube based devices. Electroanalysis, $\quad 20, \quad 558-562$. https://doi.org/10.1002/elan.200704080

Loudhaief, N., Ben Salem, M., Labiadh, H. and Zouaoui, M. (2020). electrical properties and fluctuation induced conductivity studies of bibased superconductors added by $\mathrm{PtCu}$ nanoparticles synthesized through the aqueous route. Materials Chemistry and Physics, 242, 122464. https://doi.org/10.1155/2013/898607

Norwitz, G., Nataro, N. and Keliher, P.N., (1986). Study of the steam distillation of phenolic compounds using ultraviolet spectrometry. Analytical Chemistry, 58, 639-641. https://doi.org/10.1021/ac00294a034

Nistor, C., Oubiña, A., Marco, M.P., Barceló, D. and Emnéus, J. (2001). Competitive flow 1mmunoassay with fluorescence detection for determination of 4-nitrophenol. Analytica Chimica Acta, 426, 185-195. https://doi.org/10.1016/S0003-2670(00)00825-4

Puig, D., Silgoner, I., Grasserbauer, M. and Barceló, D. (1997). Part-per-trillion level determination of priority methyl-, nitro-, and chlorophenols in river water samples by automated on-line liquid/solid extraction followed by liquid chromatography/mass spectrometry using atmospheric pressure chemical 1onization and ion spray interfaces. Analytical Chemistry, 69, 27562761. https://doi.org/10.1021/ac961256j

Saadati, F., Ghahramani, F., Shayani-jam, H., Piri, F. and Yaftian, M.R. (2018). synthesis and characterization of nanostructure molecularly Imprinted polyaniline/graphene oxide composite as highly selective electrochemical sensor for detection of p-nitrophenol. Journal of the Taiwan Institute of Chemical Engineers, 86, 213-221. https://doi.org/10.1016/j.jtice.2018.02.019

Schummer, C., Groff, C., Al Chami, J., Jaber, F. and Millet, M. (2009). analysis of phenols and nitrophenols in rainwater collected simultaneously on an urban and rural site in east of france. Science of the Total Environment, 407, 5637-5643.

https://doi.org/10.1016/j.scitotenv.2009.06.051

Song, D., Xia, J., Zhang,F., Bi, S., Xiang, W., Wang, Z., Xia, L., Xia, Y., Li, Y. and Xia, L. (2015). Multiwall carbon nanotubespoly(diallyldimethylammonium chloride)graphene hybrid composite film for simultaneous determination of catechol and hydroquinone. Sensors and Actuators B: Chemical, 206, 111118. https://doi.org/10.1016/j.snb.2014.08.084

Sreeprasad, T.S., Samal, A.K. and Pradeep, T. (2009). Tellurium nanowire-1nduced room temperature conversion of graphite oxide to leaf-like graphenic structures. The Journal of Physical Chemistry $\quad C, \quad 113, \quad 1727-1737$. https://doi.org/10.1021/jp8084777

Topçu, E., Dağcı, K. and Alanyalığlu, M. (2016). Freestanding graphene/poly(methylene blue)/AgNPs composite paper for electrochemical sensing of NADH. Electroanalysis, 28, 2058-2069. https://doi.org/10.1002/elan.201600108 
Topçu, E. and Dağcı Kıranşan, K. (2018). Flexible and free-standing PtNLs-MoS2/reduced graphene oxide composite paper: A high-performance rolled paper catalyst for hydrogen evolution reaction. ChemistrySelect. 3, 5941-5949. https://doi.org/10.1002/slct.201800500

Topçu, E. and Dağcı Kıranşan, K. (2019). Flexible gold nanoparticles/rGO and thin film/rGO papers: Novel electrocatalysts for hydrogen evolution reaction. Journal of Chemical Technology and. Biotechnology, 94, 3895-3904. https://doi.org/10.1002/jctb.6187

Topçu, E. (2020). Three-dimensional, free-standing, and flexible cobalt-based metal-organic frameworks/graphene composite paper: A novel electrochemical sensor for determination of resorcinol. Materials Research Bulletin, 121, 110629.

https://doi.org/10.1016/j.materresbull.2019.1106 29

Topçu, E. and Dağcı Kıranşan, K. (2020). Electrochemical simultaneous sensing of melatonin and ascorbic acid at a novel flexible BRGO composite paper electrode. Diamond and Related Materials, 105, 107811. https://doi.org/10.1016/j.diamond.2020.107811

Umamaheswari, A. and Venkateswarlu, K. (2004). Impact of nitrophenols on the photosynthetic electron transport chain and ATP content in nostoc muscorum and chlorella vulgaris. Ecotoxicology and Environmental Safety, 58, 256-259.

https://doi.org/10.1016/j.ecoenv.2003.11.002

Wang, D.W., Li, F., Zhao, J., Ren, W., Chen, Z.G., Tan, J., Wu, Z.S., Gentle, I., Lu, G.Q. and Cheng, H.M. (2009). Fabrication of graphene/polyaniline composite paper via in-situ anodic electropolymerization for highperformance flexible electrode. ACS Nano, 3, 1745-1752. https://doi.org/10.1021/nn900297m
Yan, J. X., Leng, Y., Guo, Y., Wang, G. Q., Gong, H., Guo, P. Z., Tan, P. H., Long, Y. Z., Liu, X. L. and Han, W. P. (2019). Highly conductive graphene paper with vertically aligned reduced graphene oxide sheets fabricated by improved electrospray deposition technique. ACS Applied Material Interfaces, $\quad 11, \quad 10810-10817$. https://doi.org/10.1021/acsami.8b19811

Yu, S., Hu, J. and Wang, J. (2010). Gamma radiationinduced degradation of p-nitrophenol (PNP) in the presence of hydrogen peroxide $(\mathrm{H} 2 \mathrm{O} 2)$ in aqueous solution. Journal of Hazardous Material, $\quad 177, \quad 1061-1067$. https://doi.org/10.1016/j.jhazmat.2010.01.028

Zhang, H., Fei, C., Zhang, D. and Tang, F. (2007). Degradation of 4-nitrophenol in aqueous medium by electro-fenton method. Journal of Hazardous Material, $\quad$ 145, 227-232. https://doi.org/10.1016/j.jhazmat.2006.11.016

Zhang, C., Govindaraju, S., Giribabu, K., Huh, Y.S. and Yun, K. (2017). AgNWs-PANI nanocomposite based electrochemical sensor for detection of 4nitrophenol. Sensors and Actuators B: Chemical, 252, 616-623. https://doi.org/10.1016/j.snb.2017.06.039

Zhao, A., Zhang, Z., Zhang, P., Xiao, S., Wang, L., Dong, Y., Yuan, H., Li, P., Sun, Y., Jiang, X. and Xiao, F. (2016). 3D nanoporous gold scaffold supported on graphene paper: freestanding and flexible electrode with high loading of ultrafine PtCo alloy nanoparticles for electrochemical glucose sensing. Analytica Chimica Acta, 938, 63-71.

https://doi.org/10.1016/j.aca.2016.08.013

Zhong, J., Li, L., Waqas, M., Wang, X., Fan, Y., Qi, J.,, Yang, B., Rong, C., Chen, W. and Sun, S. (2019). Deep eutectic solvent-assisted synthesis of highly efficient ptcu alloy nanoclusters on carbon nanotubes for methanol oxidation reaction. Electrochimica Acta, 322, 134677. https://doi.org/10.1016/j.alectroacta.2019.13467 7 